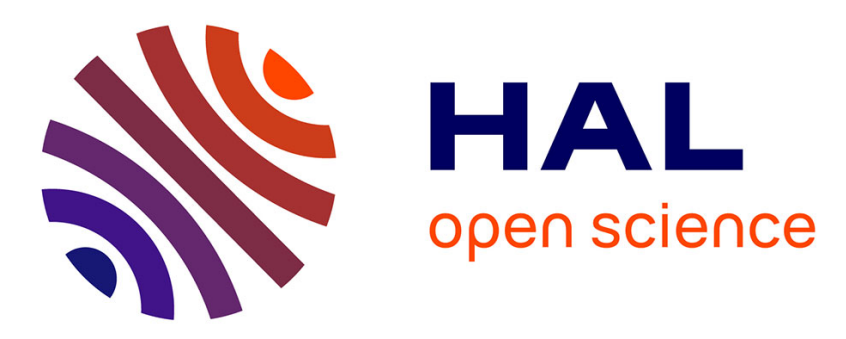

\title{
Full-scale flying shape measurement of offwind yacht sails with photogrammetry
}

Julien D. Deparday, Patrick Bot, Frédéric Hauville, Benoît Augier, Marc Rabaud

\section{- To cite this version:}

Julien D. Deparday, Patrick Bot, Frédéric Hauville, Benoît Augier, Marc Rabaud. Full-scale flying shape measurement of offwind yacht sails with photogrammetry. Ocean Engineering, 2016, 127, pp.135-143. 10.1016/j.oceaneng.2016.09.043 . hal-01379626

\section{HAL Id: hal-01379626 https://hal.science/hal-01379626}

Submitted on 11 Oct 2016

HAL is a multi-disciplinary open access archive for the deposit and dissemination of scientific research documents, whether they are published or not. The documents may come from teaching and research institutions in France or abroad, or from public or private research centers.
L'archive ouverte pluridisciplinaire HAL, est destinée au dépôt et à la diffusion de documents scientifiques de niveau recherche, publiés ou non, émanant des établissements d'enseignement et de recherche français ou étrangers, des laboratoires publics ou privés. 


\title{
Full-scale flying shape measurement of offwind yacht sails with photogrammetry
}

\author{
Julien Deparday ${ }^{\mathrm{a}}$, Patrick Bot ${ }^{\mathrm{a}, *}$, Frederic Hauville ${ }^{\mathrm{a}}$, Benoit Augier ${ }^{\mathrm{a}}$, Marc Rabaud $^{\mathrm{b}}$ \\ a Naval Academy Research Institute - IRENAV CC600, 29240 BREST Cedex 9, France \\ b Laboratoire FAST, Univ. Paris-Sud, CNRS, UniversitéParis-Saclay, F-91405 Orsay, France
}

\begin{abstract}
A B S T R A C T
Yacht downwind sails are complex to study due to their non-developable shape with high camber and massively detached flow around thin and flexible membranes. Numerical simulations can now simulate this strong FluidStructure Interaction, but need experimental validation. It remains complex to measure spinnaker flying shapes partly because of their inherent instability, like luff flapping. This work presents full-scale experimental investigation of spinnaker shapes with simultaneous measurement of aerodynamic loads on the three sail corners, with navigation and wind data. The experimental set-up and photogrammetric method are presented. Results are analysed in the whole range of apparent wind angle for this sail. The spinnaker shape shows dramatic variations and high discrepancies with the design shape. The photogrammetric measurement produces the full 3D flying shape with a satisfactory accuracy. Even if only steady state results are given here, this new system enables time-resolved measurement of flying shapes and thus flapping of spinnakers to be investigated, which is valuable for yacht performance optimisation. On top of sailing yacht applications, the method is useful in any application where a non-developable 3D shape is to be determined, and particularly when it results from the Fluid Structure Interaction of a flexible structure with a complex flow.
\end{abstract}

\section{Introduction}

Performances achieved by recent racing yachts demonstrate the massive improvements made in yacht design, materials and fabrication. In hull design, rigging design or sail design, more and more detailed research and development are used to be competitive. Understanding the physics and thus the behaviour of racing yachts have been enabled by many experimental studies combined with advanced computational resources reached nowadays. In sail design, from traditional and empirical manufacturing, the best sail designers now use high technology materials and important research and development tools (Braun and Imas, 2008; Ranzenbach et al., 2013).

The need of acquiring flying shapes is also stressed by Ranzenbach and Kleene (2002). The shape while sailing -also called flying shapegives valuable information for validation of numerical simulations, for comparison of shapes at different apparent wind angles (AWA) and with the design shape -drawn by the sailmaker.

On the water, sail shapes and performance measurements have already been carried out by the sail dynamometer boat Fujin (Masuyama, 2014). Another sail dynamometer boat called DYNA had a flying shape measurement system described in Clauss and Heisen
(2005). However those sail dynamometer boats mainly focused their experiments on upwind situations. A sail analyser method called Visual Sail Position And Rig Shape (VSPARS) is developed by the Yacht Research Unit at the University of Auckland (Le Pelley and Modral, 2008). North Sails has also developed their own tool called Advanced Sail Analyser (ASA). However, all those systems are based on a strong hypothesis for accurate measurements: the stripes painted or glued on the sail, are supposed to remain in a horizontal plane, which is not always the case for flying sails on a large range of apparent wind angles.

For downwind conditions, the physics is by far more complex than in upwind conditions due to strongly coupled Fluid-Structure Interaction between a highly curved flow and light sail cloth. Compared to upwind conditions, soft and flexible offwind sails have an inherent unsteadiness even in conditions considered "stable" (with no gust, no wind shift, on flat water and fixed trimming). This phenomenon can be spotted as a flapping at the leading edge, also called luffing. Some numerical simulations can now model the dynamic behaviour of downwind sails (Durand et al., 2014; Lombardi et al., 2012). However those simulations need validation from experiments to be confidently used in sail design optimisation. Different tools have been used to measure flying shapes of downwind sails during wind

\footnotetext{
* Corresponding author.

E-mail address: patrick.bot@ecole-navale.fr (P. Bot).
} 
tunnel experiments at smaller scale: Coordinate Measuring Machine (Ranzenbach and Kleene, 2002), Photogrammetry measurement (Fossati, 2009) with custom built Infrared cameras and Renzsch and Graf (2013). Nevertheless for wind tunnel experiments, some rules of similitude are violated. Not only is there a too small Reynolds number (about $4.10^{6}$ for full scale testing and $4.10^{5}$ for a $1 / 10$ th model) but also a different ratio of fabric weight to wind pressure is encountered as well as a different ratio of membrane stress to wind pressure. Thus fullscale experiments would complete the validation. At full scale, we have previously investigated pressure evolution during luffing (Deparday et al., 2014; Motta et al., 2015).

To measure the shape of a thin flexible surface several methods have been developed. Photogrammetry and videogrammetry using dot projection has been used on solar sails by NASA (Pappa et al., 2003). Stereophotogrammetry permits to measure deformations of a flexible wing in a wind tunnel (Black et al., 2010). But only small displacements and wrinkles are measured. Thin flexible surfaces like a spinnaker can have large displacements, in an order of magnitude of 1-5 m. Techniques to measure the displacement of a surface exist e.g. the optical profilometric technique measuring free-surface deformations using fringe pattern projection (Cobelli et al., 2009). However for those methods a controlled environment is required. Salzmann and Fua (2011) developed a model using a deforming mesh corresponding to the size of the object and only one camera. Nevertheless given the large area of the spinnaker, it is not guaranteed the whole sail is in the field of view of only one camera fixed on the deck of the sailing yacht. Those last years laser measuring tools like LIDAR (LIght Detection and RAnging) have been improved and can be used to measure flexible sails. However because of the large time necessary to scan the whole sail, dynamic measurement might be difficult to obtain. The sampling rate and the accuracy can significantly decrease with moderate cost laser measuring tools. Considerable work needs to be achieved to obtain accurate data, like the custom patented system developed by Fossati et al. (2015a) using a "Time-Of-Flight" radar to detect flying shapes. It will be used on their sail dynamometer boat (Fossati et al., 2015b).

To obtain a 3D-shape of a flying spinnaker, we decided to use a photogrammetry process. In Mausolf et al. (2011), full-scale flying shapes of spinnakers were captured using a photogrammetry process with 4 cameras placed on motorboats all around the sailing yacht, which requires manpower. In addition with independent and spaced cameras, synchronization is hard to obtain with all the cameras and with the other time-resolved data. Moreover they are on moving spots relative to the sailing yacht, which is not convenient for time-resolved flying shape measurements. Furthermore rigid-inflatable boats create waves and can hamper experiments.

Moreover, those last couple of years have witnessed an increase in the quality of cameras and a considerable cost reduction. High resolution cameras are now more affordable for experiments. If the positions of cameras are unknown, a minimum of 3 photographs is required for photogrammetry measurement. However for redundancy and better accuracy, more photographs are needed. We decided to use six High Definition cameras with wide fields of view to see the sail from different angles. They were fixed on the sailing yacht on the deck. The actual locations of the cameras do not need to be a priori known for flying shape reconstruction. At last, placing cameras on deck avoids occlusion issues with the mainsail.

In this paper, we present a full-scale testing where aerodynamic loads and flying shape are simultaneously measured. Those data are time-resolved to be used for validation of numerical models and to better assess unsteady aerodynamics of offwind sails taking into account luffing for example. We present here the experimental setup and the first steady results in the whole range of apparent wind angle for this sail, from $\mathrm{AWA} \approx 60^{\circ}$ up to AWA $\approx 140^{\circ}$. The accuracy of the photogrammetric flying shape acquisition system is discussed. Then flying shapes are compared between each other. We present a new

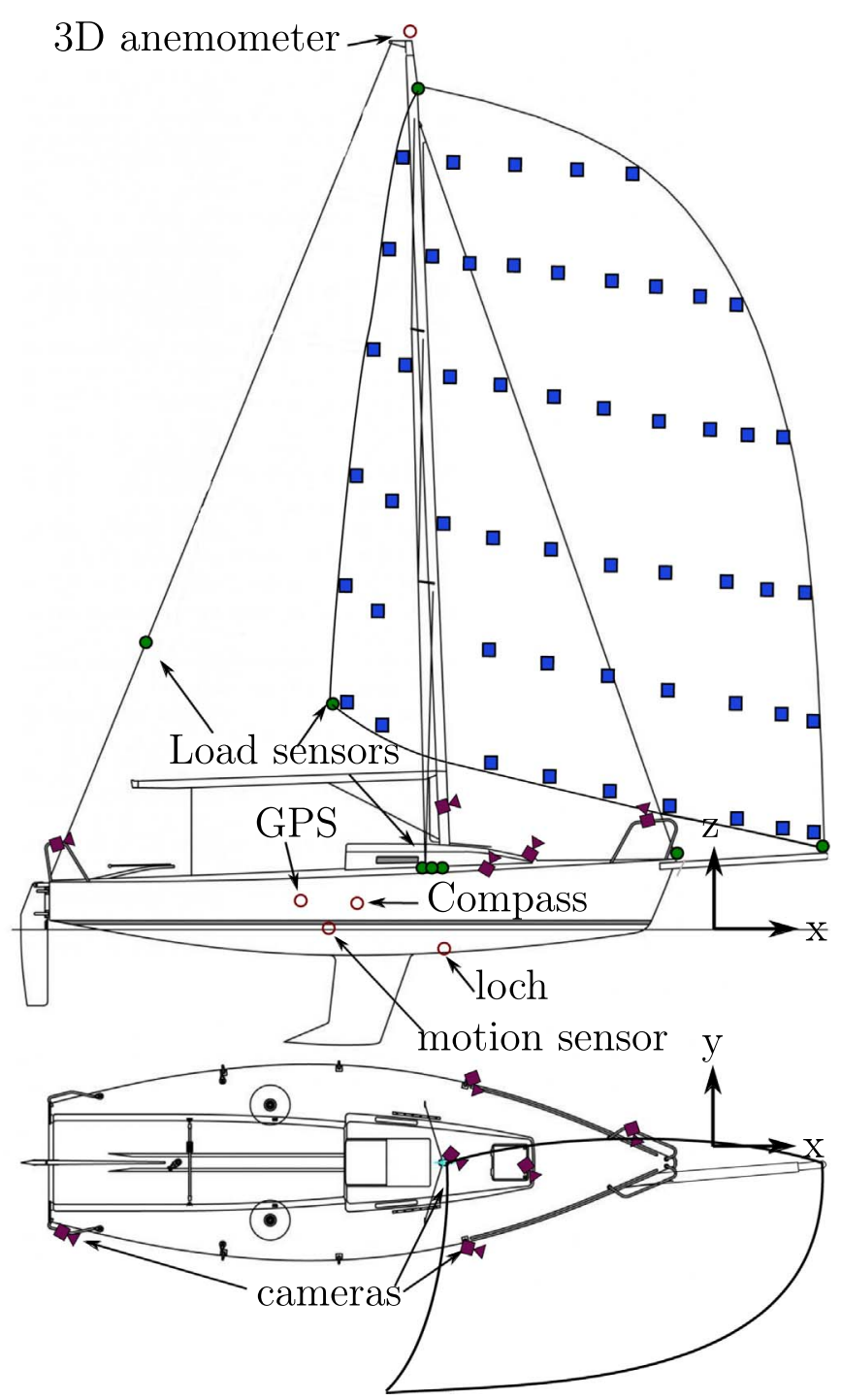

Fig. 1. General arrangement of the experimental set-up on the J/80. 11 load sensors (green discs), 6 cameras (purple objects), and wind and boat sensors (red circles). Sail markers (blue squares). (For interpretation of the references to color in this figure legend, the reader is referred to the web version of this article.)

method for comparison using the volume distribution. It displays the 3D camber of the sail, i.e. the depth of the sail from the plane created by the 3 corners of the spinnaker (head, tack and clew). The last section gives a comparison between the design shape and the flying shapes.

\section{Experimental setup}

While sailing downwind, we simultaneously measured the flying shape of the spinnaker as well as the loads on the rigging and on the corners of the spinnaker, the motion of the boat and the navigation parameters including the wind. We used a $\mathrm{J} / 80$ class yacht, an $8 \mathrm{~m}$ one-design cruiser racer. A tri-radial spinnaker with a surface of $S=68.5 \mathrm{~m}^{2}$ with a $12 \mathrm{~m}$ long rounded luff was hoisted. Fig. 1 presents the general layout of the experimental setup..

A repeatable procedure was applied during experiments. All data were recorded "on the flow", at their own rate using a dedicated realtime acquisition system, Compact Rio from National Instruments. That is, as soon as a sensor acquires a new measurement, the value is transmitted to the real-time acquisition system which instantaneously timestamps the received value. Fig. 2 presents the centralisation of all data. It shows that only the Compact Rio clock is used to timestamp different data or to trigger a laser flashing on the sails to synchronise 


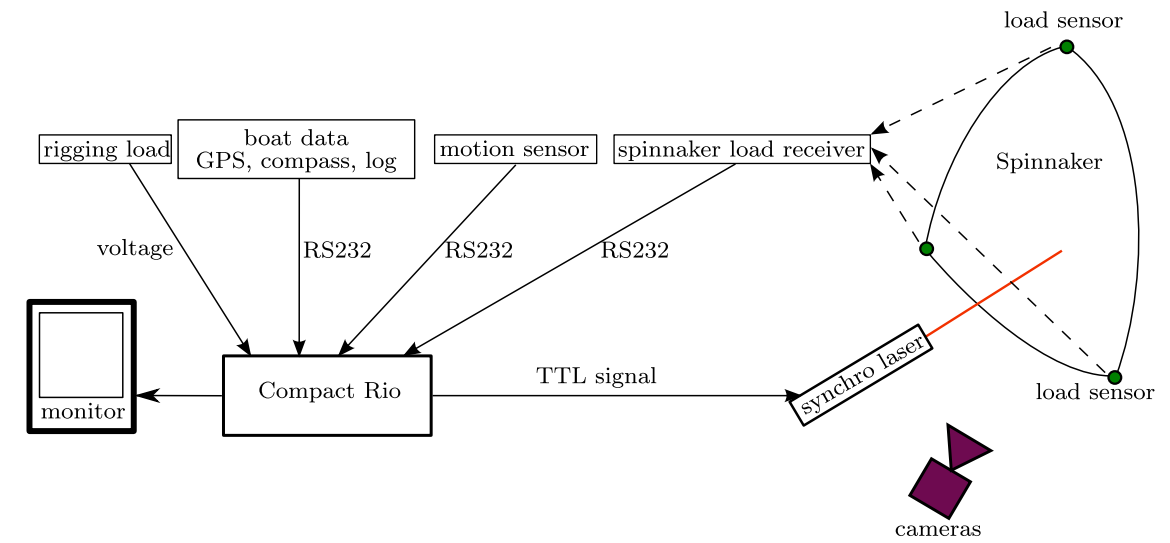

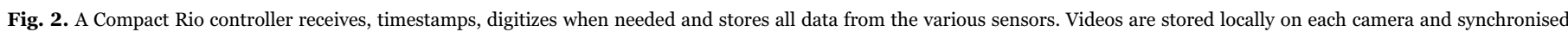
during post-processing thanks to laser flashes triggered by the controller at known timestamps. A monitor allows live visualisation and control of the system except videos.

the videos during the post-processing stage. After experiments, a postprocessing routine is used to interpolate data and to obtain synchronous signals for easier analysis. The resampling rate is $25 \mathrm{~Hz}$, the frame rate of the cameras. To ease and speed up comparison with numerical simulations, for the experiments described in this paper, the mainsail was not hoisted. Nevertheless with the present system, the flying shape of the spinnaker can be acquired with the mainsail up. For more technical details about the real-time acquisition system, the reader is referred to Deparday (2016)..

\subsection{Loads}

Aerodynamic loads are measured using strain gauges. Forestay, shrouds, backstay are equipped with dedicated instrumented turnbuckles and shackles. This measurement system for standing rigging is more described in Augier et al. (2012). The measurement error is less than $2 \%$ of the measurement range of $5000 \mathrm{~N}(10000 \mathrm{~N}$ for the shrouds and forestay). The sampling frequency is $25 \mathrm{~Hz}$. The sensors on the standing rigging are wired to the real-time acquisition controller which has a dedicated acquisition system for strain gauges. The three corners of the spinnaker (head, tack and clew) are fitted with dedicated strain gauges communicating with the controller via a wireless low consumption ZigBee protocol. The error of measurement and the sampling frequency are identical to those for standing rigging (i.e. $2 \%$ of the measurement range and $25 \mathrm{~Hz}$ ).

\subsection{Boat data}

Speed and course over ground from a GPS, speed and course above water from a speedo and a compass are gathered by a $\mathrm{NKE}^{\circledR}$ interface. These navigation data are also sent at various sampling frequencies from 1 to $5 \mathrm{~Hz}$, to the programmable automation controller using serial communication with NMEA-type sentences.

The apparent wind is measured at $10 \mathrm{~Hz}$ by a 3-axis ultrasonic anemometer located $1 \mathrm{M}$ above the mast head $-1.6 \mathrm{M}$ above the spinnaker head-, which is typical of a yacht in racing conditions. Note that the flow is affected by the sails in a large area (called upwash effect). Because this deflection is very difficult to determine in full-scale testing and varies with the apparent wind angle (AWA), speed (AWS) and sails' trim, we chose to refer to the AWA and AWS as measured by the mast head unit, that are the values commonly used by sailors and designers.

\subsection{Flying shape acquisition}

To obtain a 3D-shape of a flying spinnaker, we used a photogrammetry process.

The sail is fitted with 51 dark blue markers $100 \times 100 \mathrm{~mm}^{2}$ wide at discrete points as shown in Fig. 1. Six rows of targets are stuck on the sail cloth dividing the luff and leech in 6 equidistant sections. On these rows, targets are evenly distributed from the leading edge to the trailing edge. An additional target is placed in the first $10 \%$ of the row in order to acquire a more accurate leading edge curve. The three corners (head, tack and clew) are also marked. Target edges are automatically detected and the centre is determined as the target barycentre, with a sub-pixel interpolation to increase the accuracy.

From previous trials and 3D sketching on the yacht CAD model, 6 outdoor purpose cameras are placed to observe the most of the spinnaker for a large range of apparent wind angle (from $70^{\circ}$ to $140^{\circ}$ ). Three cameras is the minimum required. However, the more the better for redundancy and to increase accuracy. Nevertheless, too many cameras close to each other do not enhance the accuracy, since tight angles between cameras increase the error in depth. Using 6 cameras with a wide field of view -about $150^{\circ}$ - is a good compromise for such a sail. Two of the cameras are GoPro Hero 3 Black with a resolution of $2560 \times 1440$ ( 3.7 Mpixels). The others ( 3 GoPro Hero 2 and 1 GoPro Hero 3 Silver) have a resolution of $1920 \times 1080$ (2.07Mpixels). The frame rate is $25 \mathrm{~Hz}$. The videos are stored locally in micro-SD cards. The cameras are positioned on the sailing yacht at vantage points, on the pushpit, pulpit, deck-hull connection (starboard and portside), on the foredeck and on the mast $-1.5 \mathrm{~m}$ up from the deck- (see Fig. 1). However the actual locations of the cameras do not need to be a priori known for the flying shape reconstruction. The cameras are switched on simultaneously. The post-synchronisation of every video with other data is possible thanks to a laser aiming the sail every $10 \mathrm{~s}$ during $0.1 \mathrm{~s}$. This laser signal is also recorded with all the other time-resolved data.

During the experiments, movies are taken from these 6 different positions on the sailing yacht.

An algorithm of photogrammetry from the software PhotoModeler developed by Eos Systems (2015) is used. The software Photomodeler is used in many research fields including space and aeronautics (Pappa et al., 2003; Black et al., 2010) as well as sailing aerodynamics with wind tunnel experiments (Renzsch and Graf, 2013). From each image the position of a target is known in a $2 \mathrm{D}$ space. The third coordinate, the depth is computed where the perspective rays of the same target from different images are intersected (see Fig. 3). Those targets create a 3D point cloud which needs to be scaled and rotated. From different precise measured distances (i.e. between spreaders, from tack point to mast foot, etc.), these 3D targets are positioned in a reference frame with $\mathrm{x}$ along the longitudinal axis of the boat, $\mathrm{y}$ to portside and $\mathrm{z}$ pointing upwards..

For more details in the principles of close-range photogrammetry, the reader is referred to Kraus and Waldhäusl (1993).

Finally, these points are lofted to create spline curves. From those curves, a Non Uniform Rational B-Splines (NURBS) surface is created 


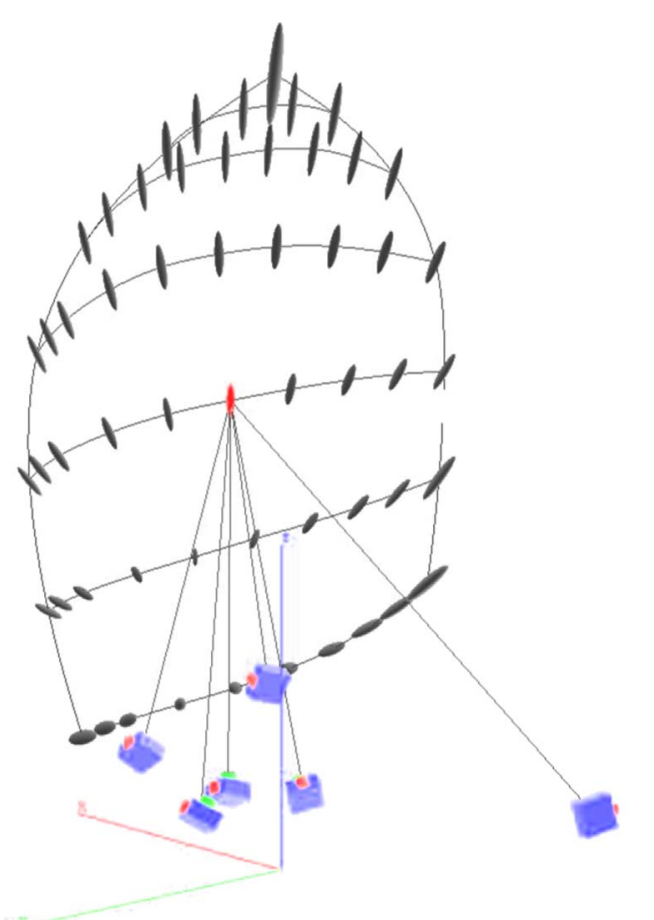

Fig. 3. Perspective rays (black lines) from cameras (in blue) to one point on the spinnaker (in red). Every bulb represents the confidence region for every point. Bulbs are scaled up 20 times. (For interpretation of the references to color in this figure legend, the reader is referred to the web version of this article.)

to represent the 3D-shape of the flying spinnaker.

Before the experiments, a thorough calibration of each camera is carried out. The focal length, principal points and distortion due to the fish-eye lens are determined for each camera. 225 coded targets positioned in a box are detected at 12 different positions by the same camera in the "on-water experiment" configuration (watertight housing, water repellent,...). After calculating the 3D positions of the photographs, the intrinsic parameters of the camera are modified in order to optimise the precision of the 3D positions of every target. The calibration algorithm is part of the software Photomodeler.

Fig. 4 shows the strong distortion due to the "fish-eye" lens corrected by the calibration process. The obtained calibration is good, considering the low-cost cameras used with a wide field of view $\left(150^{\circ}\right)$. For more quantitative details on the calibration of the cameras, the reader is referred to Deparday (2016)..

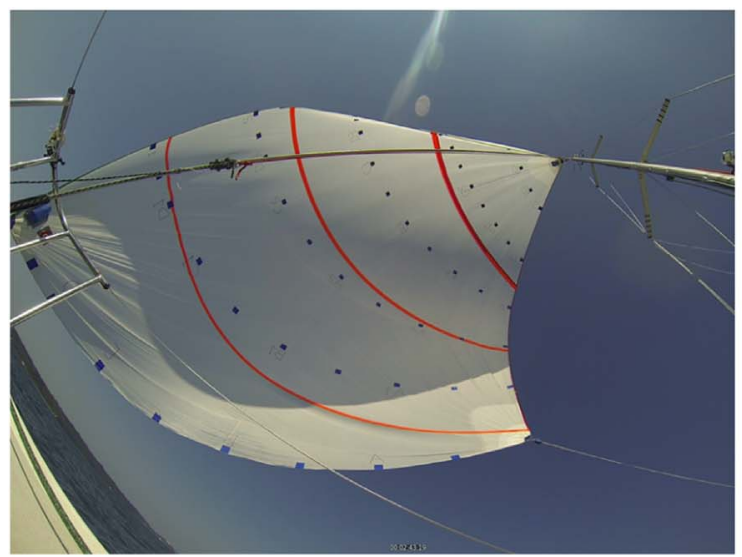

Table 1

Standard deviation in $\mathrm{mm}$ based on the post-processing covariance matrix of the $3 \mathrm{D}$ object points. Three last columns decompose the average precision in the boat frame (X longitudinal, Y portside and $\mathrm{Z}$ upwards).

\begin{tabular}{lllll}
\hline AWA & $\begin{array}{l}\text { Average Precision } \\
(\mathrm{mm})\end{array}$ & $\begin{array}{l}\text { X Precision } \\
(\mathrm{mm})\end{array}$ & $\begin{array}{l}\text { Y Precision } \\
(\mathrm{mm})\end{array}$ & $\begin{array}{l}\text { Z Precision } \\
(\mathrm{mm})\end{array}$ \\
\hline $64^{\circ}$ & 38 & 13 & 12 & 29 \\
$96^{\circ}$ & 30 & 12 & 10 & 24 \\
$124^{\circ}$ & 27 & 11 & 9 & 21 \\
$141^{\circ}$ & 21 & 9 & 7 & 16 \\
\hline
\end{tabular}

\subsection{Procedure}

Experiments have been carried out on a $\mathrm{J} / 80$ yacht, in the bay of Brest, offshore Ecole Navale in July 2014. Wind direction was North East, wind average speed $12 \mathrm{kn}(6.2 \mathrm{~m} / \mathrm{s})$ with gusts at $15 \mathrm{~m} / \mathrm{s}(7.7 \mathrm{~m} /$ $\mathrm{s}$ ), flat water (wave height $\approx 0.1 \mathrm{~m}$ ).

A detailed procedure helps for correct measurements to be repeatable and usable. Every test is repeated several times for every apparent wind angle (AWA).

- Sail at a constant given apparent wind angle (AWA).

- Spinnaker is slightly overtrimmed (i.e. no flapping of the leading edge) for one minute minimum.

- During the post-processing routine, $20 \mathrm{~s}$ long periods were labelled "stable" when the standard deviation of the apparent wind angle (AWA) was below $6^{\circ}$ and the standard deviation of the apparent wind speed (AWS) was below 10\% of the average. These threshold values revealed to be an appropriate compromise to get enough runs with a good repeatability of results for similar apparent wind angles (AWA), as shown previously with measurements of spinnaker loads, pressures and shape (Deparday et al., 2014, 2016).

\section{Results}

The spinnaker flying shape has been measured in the whole range of apparent wind angle for which this sail can be flown, from AWA $=60^{\circ}$ up to AWA $=145^{\circ}$. Characteristic results are shown below at AWA $=64^{\circ}, 96^{\circ}, 124^{\circ}$ and $141^{\circ}$ to highlight the modification of the spinnaker shape with the sailing course. For each apparent wind angle, the spinnaker is slightly overtrimmed (the luff does not flap). The flying shape is fairly constant during the $20 \mathrm{~s}$ "stable" periods described before. Thus the flying shape at one timestamp has been chosen to be representative of the average flying shape.

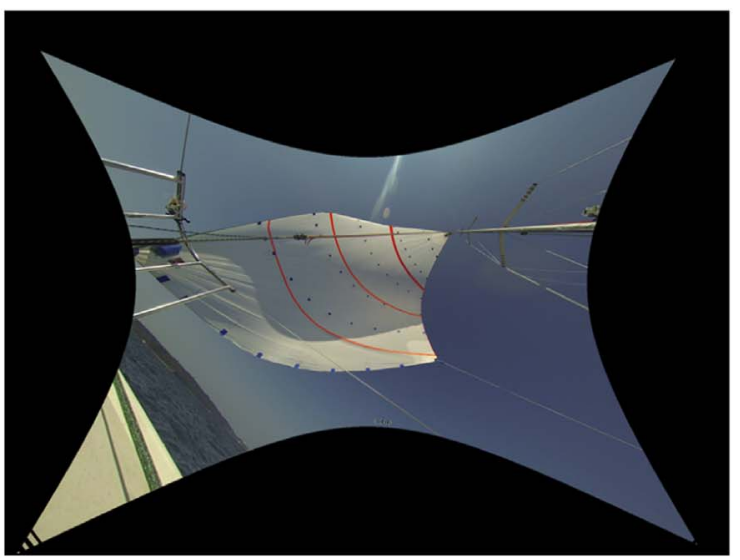

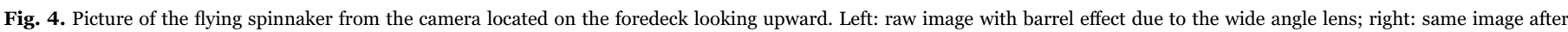
correction determined by the calibration process. Note the straight forestay which appears curved in the raw image. 
Table 2

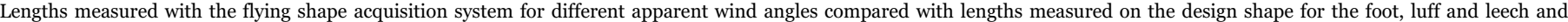

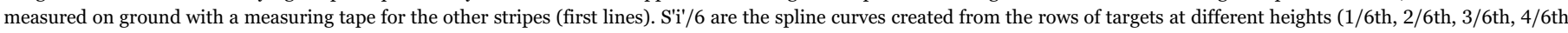

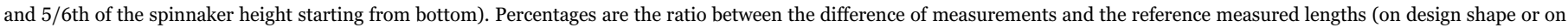
ground).

\begin{tabular}{|c|c|c|c|c|c|c|c|c|c|}
\hline \multirow[t]{3}{*}{ Reference } & \multicolumn{3}{|c|}{ Design shape } & \multicolumn{5}{|c|}{ Curved stripe lengths } & \multirow{2}{*}{$\frac{\text { Sail area }}{(S)\left(\mathrm{m}^{2}\right)}$} \\
\hline & foot $(\mathrm{m})$ & $\operatorname{luff}(\mathrm{m})$ & leech (m) & $\mathrm{S} 1 / 6(\mathrm{~m})$ & $\mathrm{S} 2 / 6(\mathrm{~m})$ & $\mathrm{S} 3 / 6(\mathrm{~m})$ & $\mathrm{S} 4 / 6(\mathrm{~m})$ & $\mathrm{S} 5 / 6(\mathrm{~m})$ & \\
\hline & 7.30 & 12.18 & 9.65 & 7.45 & 7.60 & 6.85 & 5.05 & 2.50 & 68.5 \\
\hline \multirow[t]{2}{*}{ AWA $64^{\circ}$} & 7.24 & 12.26 & 9.72 & 7.73 & 7.80 & 6.89 & 4.93 & 2.50 & 66.5 \\
\hline & $-0.84 \%$ & $0.64 \%$ & $0.77 \%$ & $3.73 \%$ & $2.62 \%$ & $0.65 \%$ & $-2.28 \%$ & $-0.05 \%$ & $-2.92 \%$ \\
\hline \multirow[t]{2}{*}{ AWA $96^{\circ}$} & 7.09 & 12.20 & 9.66 & 7.52 & 7.62 & 6.87 & 5.01 & 2.55 & 65.1 \\
\hline & $-2.90 \%$ & $0.14 \%$ & $0.06 \%$ & $0.99 \%$ & $0.26 \%$ & $0.24 \%$ & $-0.87 \%$ & $2.15 \%$ & $-4.96 \%$ \\
\hline \multirow[t]{2}{*}{ AWA $124^{\circ}$} & 7.24 & 12.39 & 9.83 & 7.72 & 7.87 & 7.07 & 5.17 & 2.59 & 68.7 \\
\hline & $-0.89 \%$ & $1.69 \%$ & $1.91 \%$ & $3.65 \%$ & $3.50 \%$ & $3.17 \%$ & $2.31 \%$ & $3.68 \%$ & $0.29 \%$ \\
\hline \multirow[t]{2}{*}{ AWA $141^{\circ}$} & 7.20 & 12.33 & 9.77 & 7.68 & 7.83 & 7.01 & 5.07 & 2.52 & 67.4 \\
\hline & $-1.38 \%$ & $1.19 \%$ & $1.19 \%$ & $3.07 \%$ & $2.98 \%$ & $2.37 \%$ & $0.31 \%$ & $0.66 \%$ & $-1.61 \%$ \\
\hline
\end{tabular}

\subsection{Accuracy of the flying shape acquisition}

The precision and accuracy are quantified for each measured flying shape.

\subsubsection{Precision}

Precision refers to the expected spread of the object point position about its estimated position. Calculating the positions of the cameras and points on the spinnaker is an iterative process. The precision is computed by the processing algorithm and gives good estimates of the errors of our system. Thus the uncertainties on positions -the residualsare analysed. For more details on the iterative process to compute the precision, see Eos Systems (2015) and Deparday (2016).

Table 1 shows the precision defined as one standard deviation based on the post-processing covariance matrix of the 3D object points. That is, there is $68 \%$ probability that the true point falls within the area defined by the precision numbers. The second column shows the average precision of all points computed for each apparent wind angle. The three next columns are the decomposition of this average precision in the boat frame. The precision is displayed and scaled up 20 times in Fig. 3 as the "confidence region" for every point.

The average precision is better than $40 \mathrm{~mm}, 0.3 \%$ of the luff length. Precision in $\mathrm{Z}$ axis (upwards) is worse than in other axes due to similar height positions of cameras (on the deck). At the head of the spinnaker, about $10 \mathrm{~m}$ away from the cameras, the angles between the perspective rays from cameras are sharp and one pixel on the image corresponds to a larger area at this distance (lower resolution). This is why in Fig. 3 points near the spinnaker head have the largest confidence region. Only $3 \%$ of all the computed points have an error larger than $100 \mathrm{~mm}$.

\subsubsection{Accuracy}

Comparing the lengths measured on the design shape with these from the flying shapes is a way to evaluate the accuracy of our system. Table 2 shows the lengths of the luff, leech and foot for the four different apparent wind angles calculated by our photogrammetry acquisition system. It also shows the lengths of the spline curves created from the different rows of targets. The lengths of the rows of targets are measured with a measuring tape on ground with no tension applied in the sail cloth.

For the edges of the sail compared with the lengths of the design shape, the errors are in average less than $1.2 \%$ for all apparent wind angles. The maximum error is found at the foot for AWA $=96^{\circ}$ with an error of $-2.90 \%$. The absolute difference is $0.11 \mathrm{~m}$ in average. The maximum absolute difference is found for the longest length, the luff, with $0.21 \mathrm{~m}$ at $\mathrm{AWA}=124^{\circ}$ and at the foot for $\mathrm{AWA}=96^{\circ}$ with $-0.21 \mathrm{~m}$.

For the stripes, the uncertainty of measurement of long curved lines on ground with a measuring tape is about $0.1 \mathrm{~m}$ mainly due to the stretch applied on the sail while measuring. Therefore the comparison with these stripes are only indicative and are not as precise as the lengths of the edges from the design shape. The errors for these stripes are less than $4 \%$ with an absolute difference of $0.28 \mathrm{~m}$ for AWA $=64^{\circ}$. Most of all the stripe dimensions displayed in Table 2 are overestimated. Moreover, lengths deduced from the measured flying shape are in average $1.7 \%$ longer than the corresponding lengths measured on ground with virtually no tension on the cloth. This is consistent with the cloth elongation when it is stretched by the aerodynamic loads (around $400 \mathrm{~N}$ ). If the reference lengths are all increased by $1.7 \%$ to roughly account for stretching, then the maximum difference drops to $0.15 \mathrm{~m}$ and the average difference to $0.09 \mathrm{~m}$, similarly to what is obtained on the sail edges. The errors on the Sail Area $S$ are a bit higher than for the lengths. Small variations of length might affect even more the sail area variations. The sail area is mainly underestimated with a maximum absolute difference of $4.9 \%$. Fig. 3 highlights that the principal direction of the uncertainty in the measurement of the points is perpendicular to the sail, and is also the depth of most of the cameras. Therefore the camber of the sail is less accurately measured and the sail area is underestimated if the sail is measured with less camber.

\subsection{Presentation of the flying shapes}

Fig. 5 presents the spinnaker flying shape for AWA $=64^{\circ}, 96^{\circ}$, $124^{\circ}$ and $141^{\circ}$, representing the whole range of this sail. Fig. $5 \mathrm{c}$ displays the bird's eye view above the mast perpendicular to the X-Y plane of the boat. The arrow represents the apparent wind direction measured at the top of the mast. At AWA $=64^{\circ}$, the clew point is aft the mast and the whole luff is on the leeward side of the boat. The luff is slightly folded as it is common at tight apparent wind angles. When the apparent wind angle is increased, the clew point goes further forward and upward. Between AWA $=64^{\circ}$ and $141^{\circ}$, the clew point position is $2.3 \mathrm{~m}$ more forward and $1.4 \mathrm{~m}$ higher and goes only $0.5 \mathrm{~m}$ more to the leeward side. Thus the clew point is closer to the "tack-head" line. Still, the same sail area is held by those 3 points while the area of the triangle head-tack-clew is smaller. Thus for a deeper AWA, the spinnaker has a more rounded shape with the luff rotating to the windward side and with the leech more opened at 3/4 height..

Fig. 5 also shows the loads measured at the sail corners for each AWA displayed. The corresponding force coefficients are between parentheses, defined as:

$C_{F}=\frac{F}{\frac{1}{2} \rho S(\mathrm{AWS})^{2}}$ 
AWA: $64^{\circ}$

AWS: $7.0 \mathrm{~m} / \mathrm{s}$

Head: $813 \mathrm{~N}$ (0.41)

Tack: $739 \mathrm{~N}$ (0.37)

Clew: $380 \mathrm{~N}(0.19)$
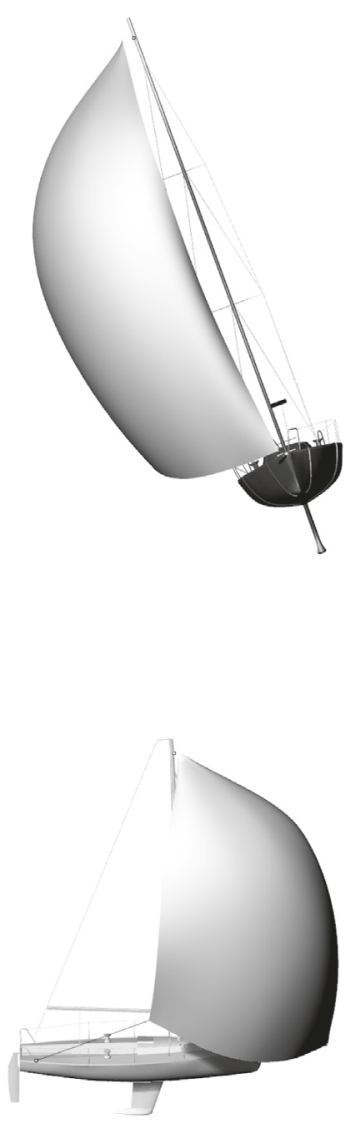

AWA: $96^{\circ}$

AWS: $5.3 \mathrm{~m} / \mathrm{s}$

Head: $720 \mathrm{~N}$ (0.63)

Tack: $618 \mathrm{~N}(0.54)$

Clew: $297 \mathrm{~N}$ (0.26)

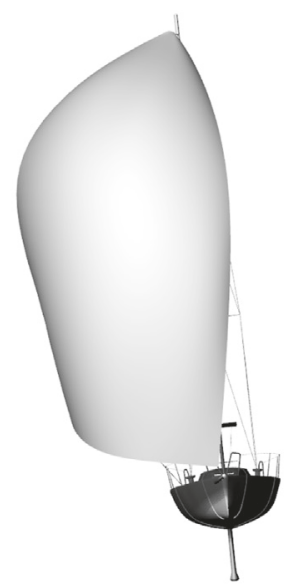

AWA: $124^{\circ}$

AWS: $4.4 \mathrm{~m} / \mathrm{s}$

Head: $434 \mathrm{~N}$ (0.55)

Tack: $361 \mathrm{~N}$ (0.46)

Clew: $184 \mathrm{~N}(0.23)$

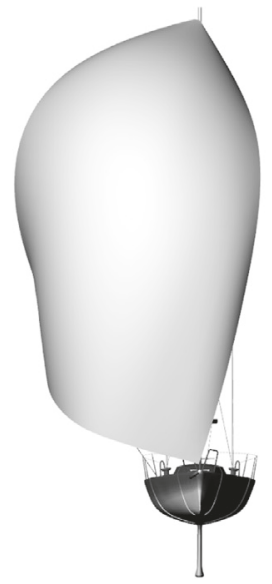

AWA: $141^{\circ}$

AWS: $3.1 \mathrm{~m} / \mathrm{s}$

Head: $176 \mathrm{~N}$ (0.45)

Tack: $100 \mathrm{~N}(0.25)$

Clew: $59 \mathrm{~N}(0.15)$

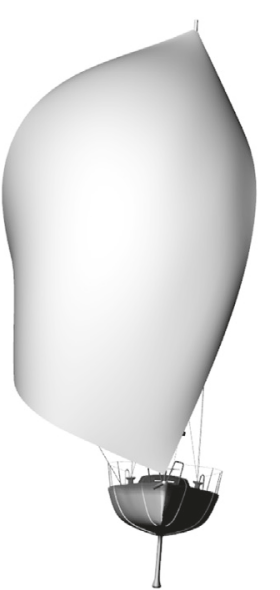

(a) View from front
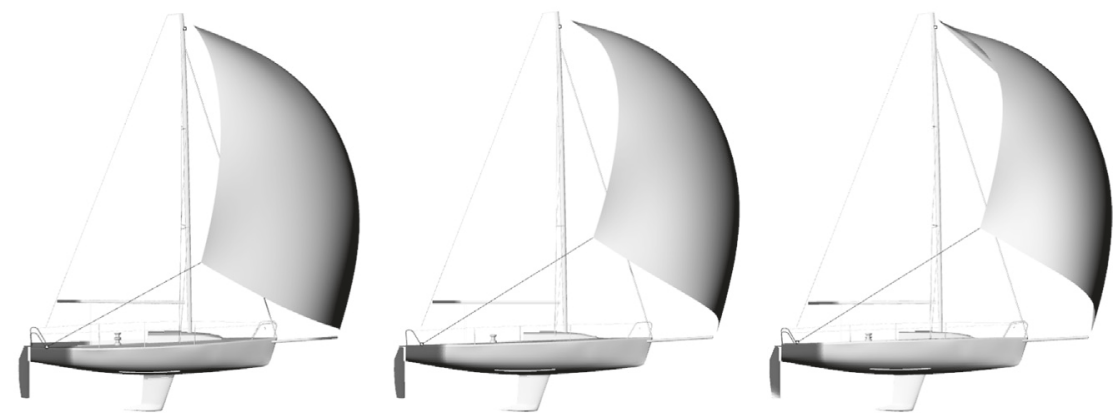

(b) View from starboard
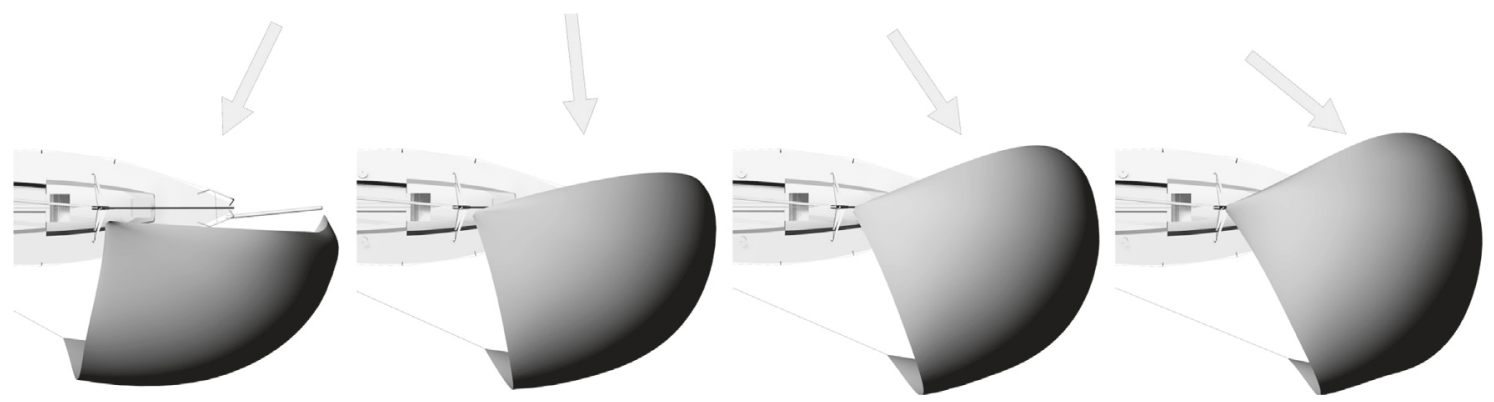

(c) Bird's eye view just above the mast head

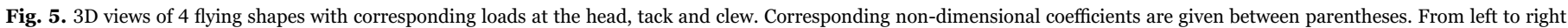
AWA: $64^{\circ}, 96^{\circ}, 124^{\circ}, 141^{\circ}$. (a) View from front. (b) View from starboard.(c) Bird's eye view just above the mast head.

with $\rho=1.22 \mathrm{~kg} / \mathrm{m}^{3}$ the density of air and $S=68.5 \mathrm{~m}^{2}$ the sail area. The apparent wind speed (AWS) is displayed in Fig. 5 and is measured by the 3-axis ultrasonic anemometer at the top of the mast.

Sail designers commonly use sections at different heights to define the shape of a sail. Leech and luff are divided into equidistant segments. Each division on the luff linked to a division on the leech defines a section at a specific height. Such sections are commonly used to design a sail and compare different shapes.

For two significant apparent wind angles, $64^{\circ}$ and $124^{\circ}$, Table 3 displays typical geometric parameters for 6 sections defining the spinnaker shape. At AWA $=64^{\circ}$ the maximum of camber is found at $1 / 3$ of the spinnaker height, while at AWA $=124^{\circ}$ the maximum of camber is found near the foot. The spinnaker bottom is flatter at $\mathrm{AWA}=64^{\circ}$ than at $\mathrm{AWA}=124^{\circ}$ with a lower camber and longer chord 
Table 3

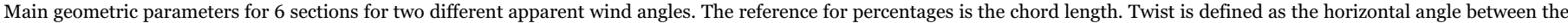
chord of a stripe and the chord of the foot. All data is measured by the photogrammetry process.

\begin{tabular}{|c|c|c|c|c|c|c|c|c|c|c|c|}
\hline \multirow[b]{2}{*}{ Section } & \multirow[b]{2}{*}{ Curve length (m) } & \multicolumn{5}{|l|}{ AWA $64^{\circ}$} & \multicolumn{5}{|l|}{ AWA 124 ${ }^{\circ}$} \\
\hline & & Chord (m) & Max camber & Draft & Twist & Entry angle & Chord (m) & Max camber & Draft & Twist & Entry angle \\
\hline foot & 7.19 & 6.58 & $20 \%$ & $49 \%$ & - & $50^{\circ}$ & 5.93 & $31 \%$ & $41 \%$ & - & $61^{\circ}$ \\
\hline $1 / 6$ & 7.66 & 6.51 & $25 \%$ & $44 \%$ & $3^{\circ}$ & $118^{\circ}$ & 6.29 & $31 \%$ & $46 \%$ & $10^{\circ}$ & $84^{\circ}$ \\
\hline $2 / 6$ & 7.78 & 6.31 & $27 \%$ & $39 \%$ & $6^{\circ}$ & $129^{\circ}$ & 6.5 & $28 \%$ & $46 \%$ & $18^{\circ}$ & $90^{\circ}$ \\
\hline $3 / 6$ & 6.96 & 5.8 & $26 \%$ & $44 \%$ & $6^{\circ}$ & $97^{\circ}$ & 6.16 & $24 \%$ & $48 \%$ & $23^{\circ}$ & $59^{\circ}$ \\
\hline $4 / 6$ & 5.04 & 4.53 & $18 \%$ & $45 \%$ & $3^{\circ}$ & $44^{\circ}$ & 4.69 & $20 \%$ & $49 \%$ & $25^{\circ}$ & $38^{\circ}$ \\
\hline $5 / 6$ & 2.54 & 2.33 & $15 \%$ & $61 \%$ & $4^{\circ}$ & $49^{\circ}$ & 2.4 & $18 \%$ & $67 \%$ & $26^{\circ}$ & $51^{\circ}$ \\
\hline
\end{tabular}

AWA $64^{\circ}$

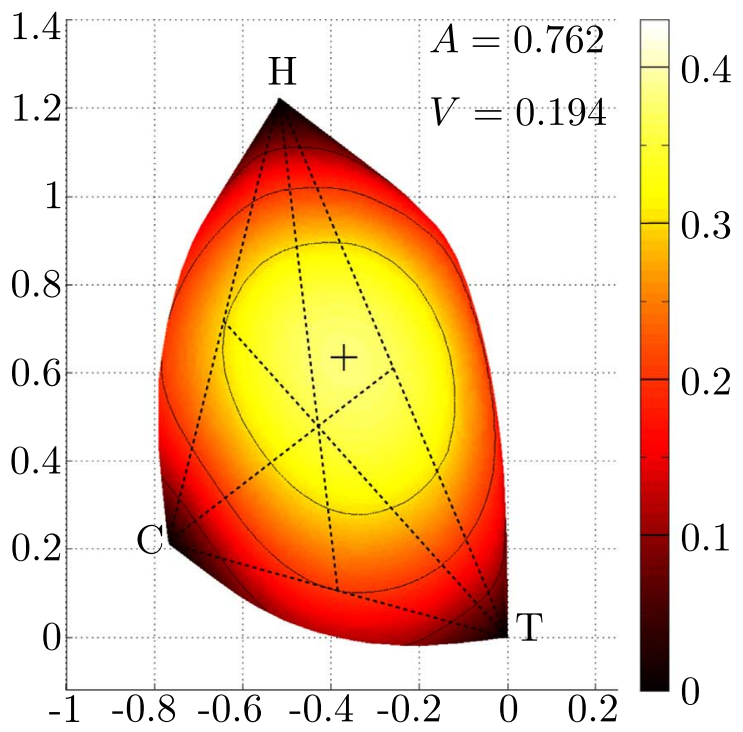

AWA $124^{\circ}$

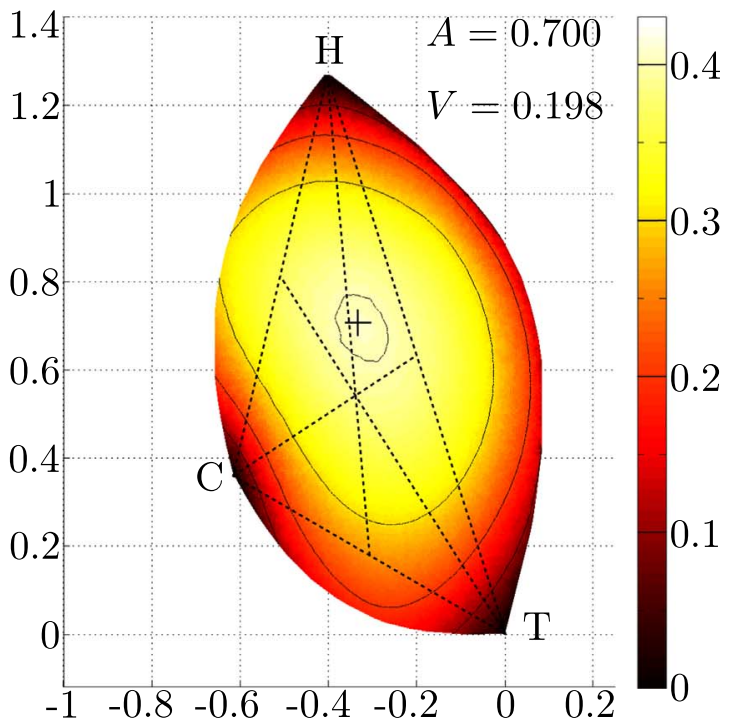

AWA $96^{\circ}$

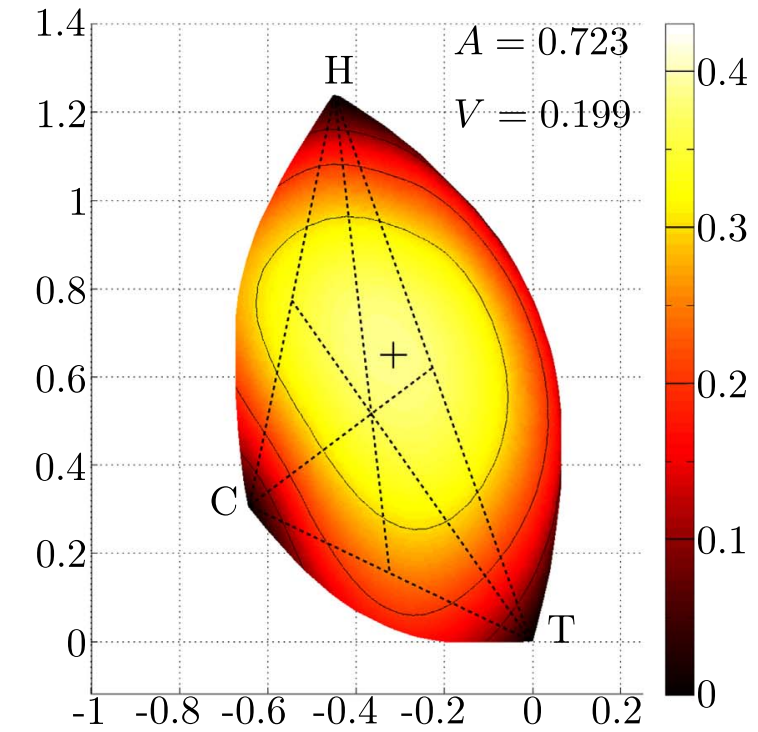

AWA $141^{\circ}$

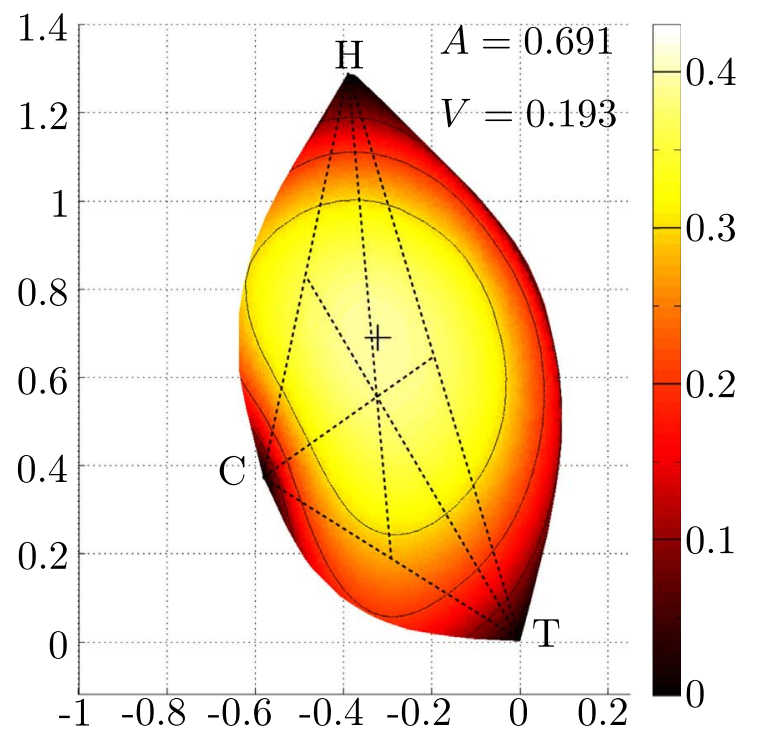

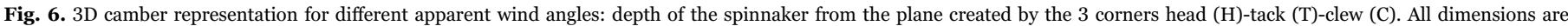

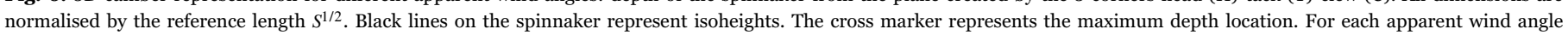
(AWA), the projected area $A$ is normalised by the sail area $S$ and the volume $V$ between the spinnaker and the HTC plane is normalised by $S^{3 / 2}$.

length for a similar draft position. For AWA $=124^{\circ}$, the spinnaker is more opened at the top producing longer chord lengths than at AWA $=64^{\circ}$. For a larger apparent wind angle, the clew position is more forward and higher allowing a more twisted shape. Table 3 indicates the twist remains very small for AWA $=64^{\circ}$, while at $\mathrm{AWA}=124^{\circ}$ the twist angle constantly increases with height to reach $26^{\circ}$ at the top of the sail. The entry angle, defined as the angle between the tangent at the leading edge and the chord, has a similar trend for 

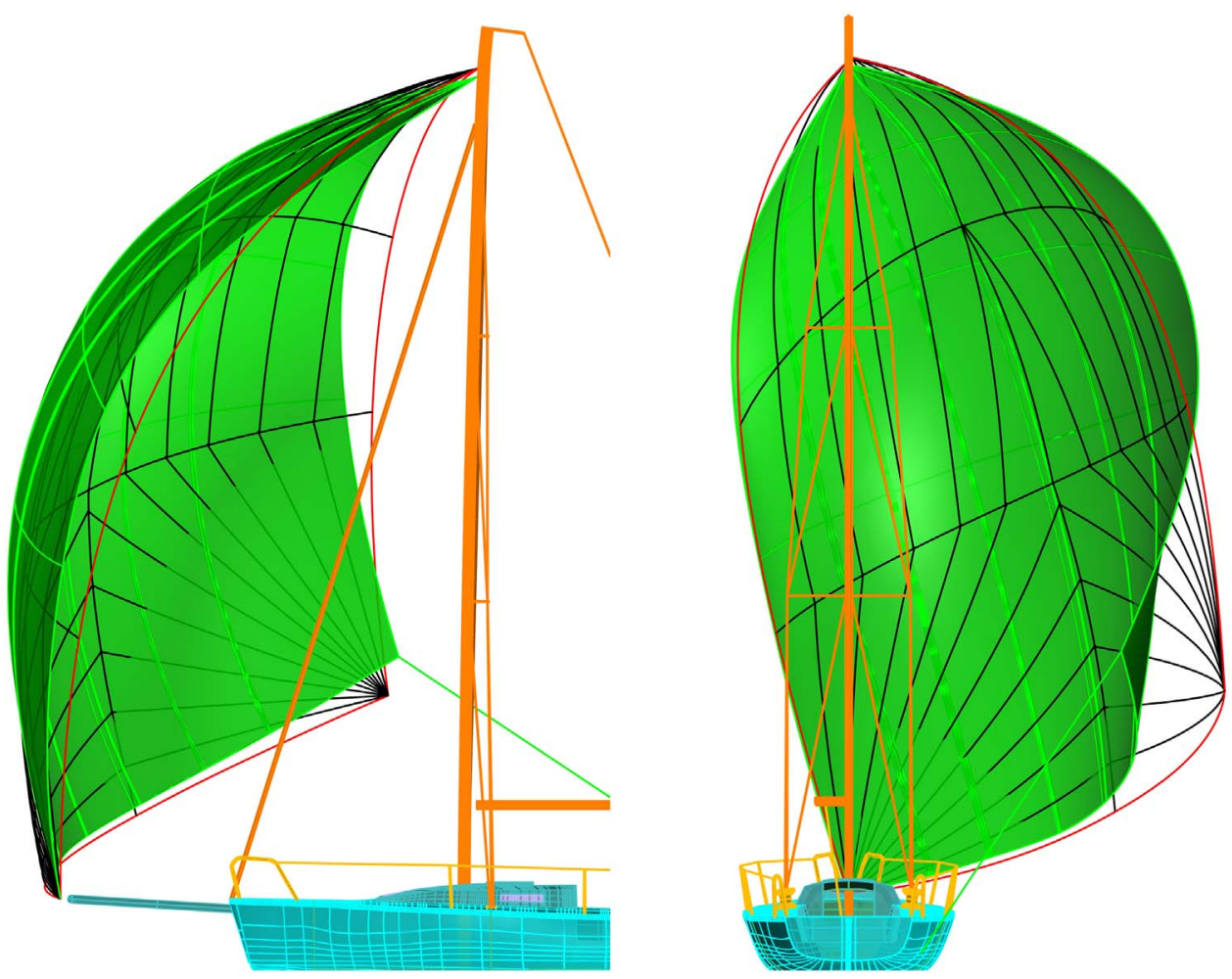

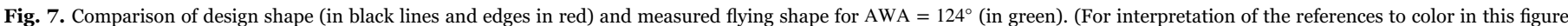
legend, the reader is referred to the web version of this article.)

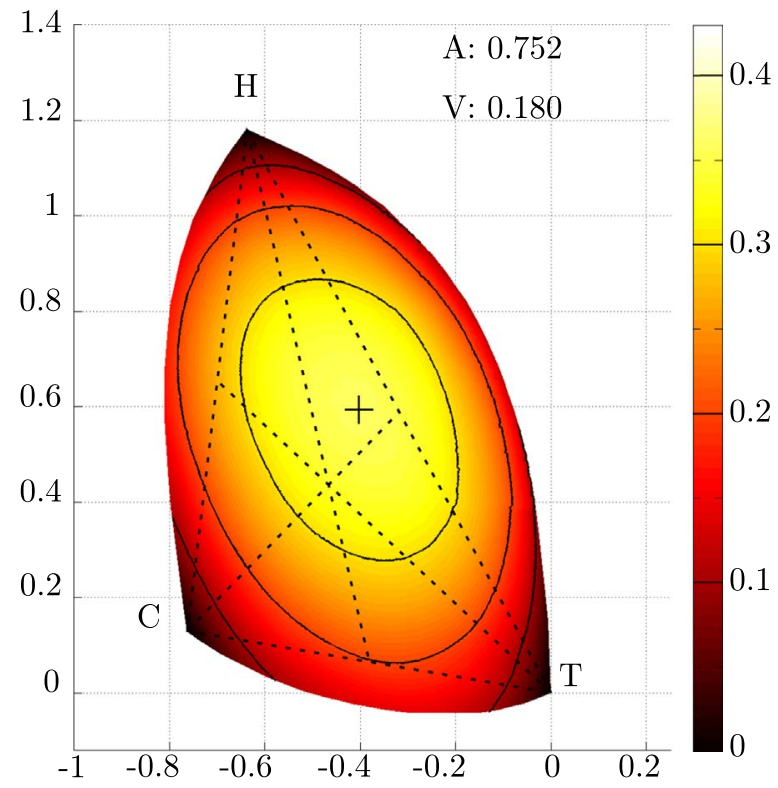

Fig. 8. 3D camber representation of the design shape: depth of the spinnaker from the plane created by the 3 corners head (H)-tack (T)-clew (C). All dimensions are normalised by the reference length $S^{1 / 2}$. Black lines on the spinnaker represent isoheights. The cross marker represents the maximum depth location. The projected area $A$ is normalised by the sail area $S$ and the volume $V$ between the spinnaker and the HTC plane is normalised by $S^{3 / 2}$.

both AWAs. The entry angle strongly increases up to $1 / 3$ height and then decreases again to reach at the top of the mast an entry angle similar to the foot. However the variations are much bigger for $\mathrm{AWA}=64^{\circ}$ with a difference of $80^{\circ}$ between the foot and $1 / 3$ height, whereas the amplitude is only about $30^{\circ}$ for AWA $=124^{\circ}$. As can be seen for tight AWA in Fig. 5, the luff is slightly folded giving higher entry angles. Since the curvature is high and varies quickly streamwise, this parameter is very sensitive.

However, the stripes are not always contained in a plane parallel to the flow. They can be curved, and have different heights at the luff and leech points. Unlike upwind sails, spinnakers are far from 2D-extruded shapes. Downwind sails are 3D objects. Therefore, those geometric sections might not be the most convenient way to quantify the 3D geometry of a spinnaker.

Fig. 6 presents the shape of the spinnaker in a different way. It shows the "3D camber", the depth of the sail projected onto the plane created by the 3 corners of the spinnaker. The " $\mathrm{H}$ " point is the head of the spinnaker fixed on the mast and " $\mathrm{T}$ " is the tack point fixed on the bowsprit of the boat. Assuming those points fixed, with this representation the position of the clew " $\mathrm{C}$ " is defined with the angles of the triangle HTC and the volume distribution of the spinnaker is displayed. This representation could facilitate the comparison between shapes.

The cross marker showing the location of the maximum of " $3 \mathrm{D}$ camber" is located slightly above and forward the centroid of the triangle "Head-Tack-Clew" (HTC). At AWA $=64^{\circ}$, the volume distribution is mainly homogeneous and circular. When the apparent wind angle is increased, the "bulb of camber" tends to have a more elongated and bended shape similar to a bean shape. Furthermore, for a deeper AWA, the maximum of depth goes slightly aft. At AWA $=141^{\circ}$, it is located at the middle of the Head median. Finally when the AWA is increased, the projected area $A$, normalised by the surface of the spinnaker $S=68.5 \mathrm{~m}^{2}$, decreases while the volume $(V)$ between the spinnaker and the HTC plane, normalised by the spinnaker surface at the power $3 / 2$ remains constant. The "3D camber" method enables characterising the different spinnaker shapes.

\subsection{Flying shapes versus design shape}

For the $J / 80$ class yacht, in a $12-16 \mathrm{kn}$ breeze, the best angle course downwind (maximum Velocity Made Good, VMG) is obtained for an AWA from $120^{\circ}$ to $130^{\circ}$. Then the spinnaker is expected to be designed for this apparent wind angle. When comparing the design shape with 
the measured flying shape at AWA $=124^{\circ}$, strong differences are observed (see Fig. 7). The design shape has less volume at half height of the sail with less rounded edges. In the real shape while sailing, the leech is more curved, more opened at $3 / 4$ height and closed at bottom due to the only control we have with the clew point.

From the 3D camber representation (Fig. 8), the design shape looks closer to the flying shape measured at AWA $=64^{\circ}$ (Fig. 6), which is an extreme sailing course for this sail and is far from the optimal VMG downwind. Moreover the projected area for the design shape is similar to the projected area for AWA $=64^{\circ}(A \approx 0.75)$. However, both shapes are not identical and the volume between the spinnaker and the HTC plane is rather different ( $V=0.180$ for the design shape, and $V=0.194$ for the flying shape at AWA $=64^{\circ}$ ).

The observed differences highlight that a CFD simulation around a spinnaker considering the geometry of the design shape will not be representative of the real sailing conditions. Resolving the flow around the real geometry then requires a Fluid-Structure simulation to account for the a priori unknown flying shape.

\section{Conclusions}

An experimental set-up has been developed on a $J / 80$ class sailing yacht to record time-resolved data of flying shapes, aerodynamic forces of the spinnaker and on the standing rigging, as well as boat motion and wind data. A new on-board system using a photogrammetry process is developed to capture the flying shape of the spinnaker. Results of this process give reliable and sufficiently accurate data to compare flying shapes for different apparent wind angles and with the design shape and thus would help sail designers and competitors.

The first static flying shapes have been captured during navigation and validated. The use of sections to define the shape of the sail surface is common but might not be the optimal solution for downwind sails because of the large curvatures and deformations. A new 3D camber representation is proposed displaying the volume distribution, the depth of the sail projected onto the plane created by the 3 corners of the spinnaker which might be a better tool to define and characterise the shapes of downwind sails.

Another advantage of this acquisition system is the possibility to acquire the inherent unsteadiness of offwind sails by resolving dynamic flying shapes. Further work aims at analysing the evolution of shapes with loads and boat data during spinnaker luff flapping and dynamic trimming of the sheet. These results will make a valuable benchmark for validation of unsteady Fluid Structure Interaction numerical simulations.

The method proved to be efficient to determine the real spinnaker flying shape resulting from the design shape to which the sail is made and the Fluid Structure Interaction with the sheered and twisted apparent wind flow. The new information provided will be very helpful to improve performances of sailing yachts. Moreover, the method can be used in any other application that needs to measure an unsteady 3D non-developable shape, particularly when it results from the Fluid Structure Interaction of a flexible structure with a complex flow.

\section{Acknowledgements}

The authors would like to thank DELTA Voiles for giving us the spinnaker and the design shape. They also would like to thank Eos Systems Inc. for their efficient help on PhotoModeler. The authors would also not forget to thank Ronan Floch from Incidences for the fruitful discussions they had together.

\section{References}

Augier, B., Bot, P., Hauville, F., Durand, M., 2012. Experimental validation of unsteady models for fluid structure interaction: application to yacht sails and rigs. J. Wind Eng. Ind. Aerodyn. 101, 53-66.

Black, J.T., Pitcher, N.a., Reeder, M.F., Maple, R.C., 2010. Videogrammetry dynamics measurements of a lightweight flexible wing in a wind tunnel. J. Aircr. 47 (1), $172-180$.

Braun, J.B., Imas, L., 2008. High fidelity CFD simulations in racing yacht aerodynamic analysis. In: Proceedings of the 3rd High Performance Yacht DesignConference. Auckland, pp. 168-175.

Clauss, G.F., Heisen, W., 2005. CFD analysis on the flying shape of modern yacht sails. In: Proceedings of the 12th International Congress of the International Maritime Association of the Mediterranean. Lisbon, pp. 87-94.

Cobelli, P.J., Maurel, A., Pagneux, V., Petitjeans, P., 2009. Global measurement of water waves by Fourier transform profilometry. Exp. Fluids 46 (6), 1037-1047.

Deparday, J., 2016. Experimental studies of Fluid-Structure Interaction on Downwind Sails. Ph.D. thesis, IRENav, UBO.

Deparday, J., Bot, P., Hauville, F., Augier, B., Rabaud, M., Motta, D., Le Pelley, D., 2016. Modal analysis of pressures on a Full-Scale Spinnaker. In: Proceedings of the 22nd Chesapeake Sailing Yacht Symposium. Annapolis, pp. 98-110.

Deparday, J., Bot, P., Hauville, F., Motta, D., Le Pelley, D.J., Flay, R. G., 2014. Dynamic measurements of pressures, sail shape and forces on a full-scale spinnaker. In: Proceedings of the 23rd HISWA Symposium on Yacht Design and Yacht Construction. Amsterdam, pp. 61-73.

Durand, M., Leroyer, A., Lothodé, C., Hauville, F., Visonneau, M., Floch, R., Guillaume, L., 2014. FSI investigation on stability of downwind sails with an automatic dynamic trimming. Ocean Eng. 90, 129-139.

Eos Systems Inc., 2015. Photomodeler 2015 User Guide.

Fossati, F., 2009. Aero-Hydrodynamics and the Performance of Sailing Yachts: The Science Behind Sailing Yachts and Their Design. International Marine/Mc Graw Hill.

Fossati, F., Bayati, I., Orlandini, F., Muggiasca, S., Vandone, A., Mainetti, G., Sala, R., Bertorello, C., Begovic, E., 2015a. A novel full scale laboratory for yacht engineering research. Ocean Eng. 104, 219-237.

Fossati, F., Mainetti, G., Malandra, M., Sala, R., Schito, P., Vandone, A., 2015b. Offwind sail flying shapes detection. In: Proceedings of the 5th High Performance Yacht Design Conference. Auckland, pp. 48-59.

Kraus, K., Waldhäusl, P., 1993. Photogrammetry Fundamentals and Standard Processes. Dümmmler Verlag, Bonn.

Le Pelley, D.J., Modral, O., 2008. VSPARS: A combined sail and rig recognition system using imaging techniques. In: Proceedings of the 3rd High Performance Yacht Design Conference. Auckland, pp. 57-66.

Lombardi, M., Cremonesi, M., Giampieri, A., Parolini, N., Quarteroni, A., 2012. A strongly coupled fluid-structure interaction model for wind-sail simulation. In: 4th High Performance Yacht Design. Auckland, pp. 212-221.

Masuyama, Y., 2014. The work achieved with the sail dynamometer boat "fujin", and the role of full scale tests as the bridge between model tests and CFD. Ocean Eng. 90, $72-83$.

Mausolf, J., Deparday, J., Graf, K., Renzsch, H., Böhm, C., 2011. Photogrammetry Based Flying Shape Investigation of Downwind Sails in the Wind Tunnel and at Full Scale on a Sailing Yacht. In: Proceedings of the 20th Cheasapeake Sailing Yacht Symposium. Annapolis, pp. 33-43.

Motta, D., Flay, R.G., Richards, P.J., Le Pelley, D., Bot, P., Deparday, J., 2015. An investigation of the dynamic behaviour of asymmetric spinnakers at full-scale. In: Proceedings of the 5th High Performance Yacht Design Conference. Auckland, pp. 76-85.

Pappa, R.S., Black, J.T., Blandino, J.R., Jones, T.W., Danehy, P.M., Dorrington, A.A., 2003. Dot-Projection Photogrammetry and Videogrammetry of Gossamer Space Structures. J. Spacecr. Rockets 40 (6), 858-867.

Ranzenbach, R., Armitage, D.,Carrau, A., 2013. Mainsail Planform Optimization for IRC 52 Using Fluid Structure Interaction. In: Proceedings of the 21st Chesapeake Sailing Yacht Symposium. Annapolis, pp. 50-58.

Ranzenbach, R., Kleene, J., 2002. Utility of flying shapes in the development of offwind sail design database. In: The High Performance Yacht Design Conference. Auckland.

Renzsch, H., Graf, K., 2013. An experimental validation case for fluid-structureinteraction simulations of downwind sails. In: Proceedings of the 21st Chesapeake Sailing Yacht Symposium. Annapolis, p. 8.

Salzmann, M., Fua, P., 2011. Linear local models for monocular reconstruction of deformable surfaces. IEEE Trans. Pattern Anal. Mach. Intell. 33, 931-944. 